\title{
Editorial
}

\section{The Nobel Prize in Physiology or Medicine 2018 Was Awarded to Cancer Therapy by Inhibition of Negative Immune Regulation}

\author{
Fukumi Furukawa ${ }^{1,2}$ \\ ${ }^{1}$ Takatsuki Red Cross Hospital, Takatsuki City, Osaka, Japan \\ ${ }^{2}$ Wakayama Medical University, Wakayama City, Wakayama, Japan
}

On October 1, The Nobel Prize in Physiology or Medicine 2018 was awarded jointly to Dr. James P. Allison and Dr. Tasuku Honjo "for their discovery of cancer therapy by inhibition of negative immune regulation.

The Nobel Assembly at Karolinska Institute released the comments that Dr. Allison and Dr. Honjo showed how different strategies for inhibiting the brakes on the immune system could be used in the treatment of cancer ${ }^{[1-5]}$. The seminal discoveries by the two laureates constitute a landmark in our fight against cancer. https://www.nobelprize.org/prizes/medicine/2018/prize-announcement/

I sincerely wish to congratulate two recipients, co-workers and many patients cooperated in clinical trials. In this journal, we have published several reviews and papers on immunity checkpoints so far. The reason is that the mission of this journal is in scientific awareness and dissemination of new immunotherapy.

I herein introduce briefly my previous report with some modification ${ }^{[6]}$. Immune checkpoints inhibitors (ICIs) have opened promising avenues in the treatment of cancer. Various blocking antibodies targeting programmed cell death -1 (PD-1) and cytotoxic T-lymphocyte-associated protein 4 (CTLA-4) are approved for human use. They significantly improved disease outcome in a number of cancer patients by boosting anti-tumor immune responses. As Seidel, Otsuka and Kabashima described in their review article ${ }^{[7]}$, mortality among advanced stage patients and the frequency of treatment-related adverse events remain high with current treatment. And, it is also noteworthy that unexpected immune related adverse effects (irAEs) appear, even when it becomes better to be administered to many cancer patients ${ }^{[8]}$. Unfortunately, the mechanisms of endocrine irAEs by ICIs, remain unclear, and optimal prevention, prediction, and treatment of the irAEs are still uncertain. However, appropriate uses and index setting related to prognosis are being studied in many fields such as dermatology ${ }^{[9]}$ and other organs ${ }^{[6,7]}$.

While solving such problems, we have to understand that the mechanisms of immunogenic cell death are now moving from concepts to the clinic. We will explain the mechanism behind ICD and how it will perhaps breathe a new life into chemotherapy use in cancer, not front and center but as a helpful hand to immunotherapy ${ }^{[10]}$.

For a long time many scientists or doctors attempted to engage the immune system in the fight against cancer. Many clinicians stared at cancer patients who were to be dying by their side, mourning their inability. However, cancer therapy by inhibition of negative immune regulation checkpoint therapy has fundamentally changed the way we view how cancer can be managed and many patients will receive much better care and cure.

\section{Acknowledgment}

This work was supported by a grant from the Japan Society for Promotion of Science.

\section{Conflicts of interest}

No conflict of interest was reported by the author.

\footnotetext{
Copyright (C) 2018 Fukumi Furukawa

doi: 10.24294/ti.v2.i1.1065

EnPress Publisher LLC.This work is licensed under the Creative Commons Attribution-NonCommercial 4.0 International License (CC BY-NC 4.0). http://creativecommons.org/licenses/ by/4.0/
} 


\section{References}

1. Ishida Y, Agata Y, Shibahara K, Honjo T (1992). Induced expression of PD-1, a novel member of the immunoglobulin gene superfamily, upon programmed cell death. EMBO J.,1992; 11(11): 3887-3895. PMID: 1396582

2. Leach DR, Krummel MF, Allison JP. Enhancement of antitumor immunity by CTLA-4 blockade. Science, 1996; 271(5256):1734-1736. PMID: 8596936

3. Nishimura H, Nose M, Hiai H, et al. Development of lupus-like autoimmune diseases by disruption of the PD-1 gene encoding an ITIM motif-carrying immunoreceptor. Immunity 1999; 11(2): 141-151. PMID:10485649

4. Hodi FS, Mihm MC, Soiffer RJ et al. Biologic activity of cytotoxic T lymphocyte-associated antigen 4 antibody blockade in previously vaccinated metastatic melanoma and ovarian carcinoma patients. Proc Natl Acad Sci USA, 2003; 100(8): 4712-4717. doi: 10.1073/pnas.0830997100

5. Okazaki T, Honjo T. PD-1 and PD-1 ligands: From discovery to clinical application. Int Immunol 2007; 19(7): 813-824. doi: 10.1093/intimm/ dxm057

6. Furukawa F. Immune checkpoint inhibitors and irAEs. Trends Immunother 2018; 2(2): 930. doi: 10.24294/ti.v2.i2.930

7. Seidel JA, Otsuka A, Kabashima K. Treating tumors with immune checkpoint inhibitors: Rationale and limitations. Trends Immunother 2017; 1(1): 2-9. doi: 10.24294/ti.v1.i1.20

8. Inaba H, Ariyasu H, Okuhira H, et al. Endocrine dysfunctions during treatment of immune-checkpoint inhibitors. Trends Immunother 2018; 2(2): 565. doi: 10.24294/ti.v2.i2.606.

9. Okuhira H, Yamamoto Y, Inaba Y, et al. Prognostic factors of daily blood examination for advanced melanoma patients treated with nivolumab. BioScience Trends. 2018; 12. doi: 10.5582/bst.2018.01158

10. Bulbul A. Immunogenic cell death: chemoimmunotherapy in the clinic. Trends Immunother 2018; Vol. 2. doi:10.24294/ti.v2.i2.970 